\title{
Influences on Post-Bariatric Surgery Satisfaction
}

Garrido, Susana; Silva, I; Gonçalves, L; Caldas, AR; Cardoso, MH

Serviço de Endocrinologia, Diabetes e Metabolismo, Centro Hospitalar do Porto - Porto, Portugal

\section{BACKGROUND}

Post-bariatric surgery satisfaction relies on psychosocial and clinical factors. A questionnaire that evaluates this variable has recently been created and validated by the authors (Post-Bariatric Surgery Satisfaction Questionnaire).

\section{AlM}

To assess the relationship between treatment satisfaction and several demographic and clinical variables.

\section{METHODS}

- Patients submitted to bariatric surgery, presenting to our Obesity Outpatient Clinic between June-December/2013

- Demographic and clinical data + Post-Bariatric Surgery Satisfaction Questionnaire (22 items, 5-point scale $-1=$ very dissatisfied, $5=$ very satisfied)

- Statistical analysis - SPSS v20.0, descriptive and inferential statistics (Mann-Whitney test, partial correlation, linear regression); $p \leq 0.05$ considered statistically significant

\section{RESULTS}

\section{CHARACTERISTICS OF THE STUDIED POPULATION $(n=86)$}

Gender (male/female), \%

Age, years ${ }^{a}$

Type of surgery (laparoscopic gastric

bypass/adjustable gastric banding), \%

Initial BMI, $\mathrm{kg} / \mathrm{m}^{2}$ a

$\%$ excess BMI lost ${ }^{\text {a }}$

Follow up time since surgery, months ${ }^{\text {a }}$

a Data expressed as median (IQR, min-max)
$14 / 86$

$50(19 ; 23-73)$

$67 / 33$

$45.9(8.4 ; 32.1-84.4)$

$68.8(34.6 ; 8.2-113.3)$

$37(56 ; 1-220)$

\section{SATISFACTION WITH TREATMENT AND GENDER}

No differences between genders

- 22 items

- Global satisfaction

\section{SATISFACTION WITH TREATMENT AND AGE}

(adjusted to percentage of excess BMI lost)

Negative correlation with "physical well-being"

$$
(r=-0.27 ; p=0.012)
$$

Negative correlation with "enhancement of movement capabilities" $(r=-0.25 ; p=0.019)$,

\section{SATISFACTION WITH TREATMENT AND FOLLOW-UP TIME SINCE SURGERY (adjusted to percentage of excess BMI lost)}

No correlation with follow-up time since surgery

- 22 items

Global satisfaction

SATISFACTION WITH TREATMENT AND PERCENTAGE OF EXCESS BMI LOST
\begin{tabular}{|l|c|c|}
\hline Goals achieved after surgery & $\boldsymbol{r}$ & $\boldsymbol{p}$ \\
\hline Weight achieved & 0.39 & $<0.001$ \\
\hline Improvement of self-esteem & 0.53 & $<0.001$ \\
\hline Way you are seen by others & 0.28 & 0.008 \\
\hline Improvement of health status & 0.34 & 0.002 \\
\hline Improvement of sexual life & 0.22 & 0.049 \\
\hline Improvement of love life & 0.36 & 0.001 \\
\hline Improvement of social life & 0.32 & 0.002 \\
\hline Improvement of emotional well-being & 0.28 & 0.008 \\
\hline Physical appearance when dressed & 0.26 & 0.017 \\
\hline Physical appearance when naked & 0.45 & $<0.001$ \\
\hline Improvement of physical well-being & 0.28 & 0.009 \\
\hline Ability to wear clothes you like & 0.29 & 0.007 \\
\hline Improvement of freedom of movements & 0.54 & $<0.001$ \\
\hline Improvement of the ability to care for personal hygiene & 0.51 & $<0.001$ \\
\hline Global satisfaction & 0.45 & 0.002 \\
\hline Improvement of professional life & 0.02 & 0.88 \\
\hline Need of chronic medication & 0.06 & 0.58 \\
\hline Eating habits & 0.13 & 0.24 \\
\hline Pleasure of eating & 0.07 & 0.53 \\
\hline Hunger sensation & -0.02 & 0.84 \\
\hline Type of food you can eat & 0.02 & 0.83 \\
\hline Amount of food you eat & 0.08 & 0.47 \\
\hline
\end{tabular}

\section{SATISFACTION WITH TREATMENT AND TYPE OF SURGERY}

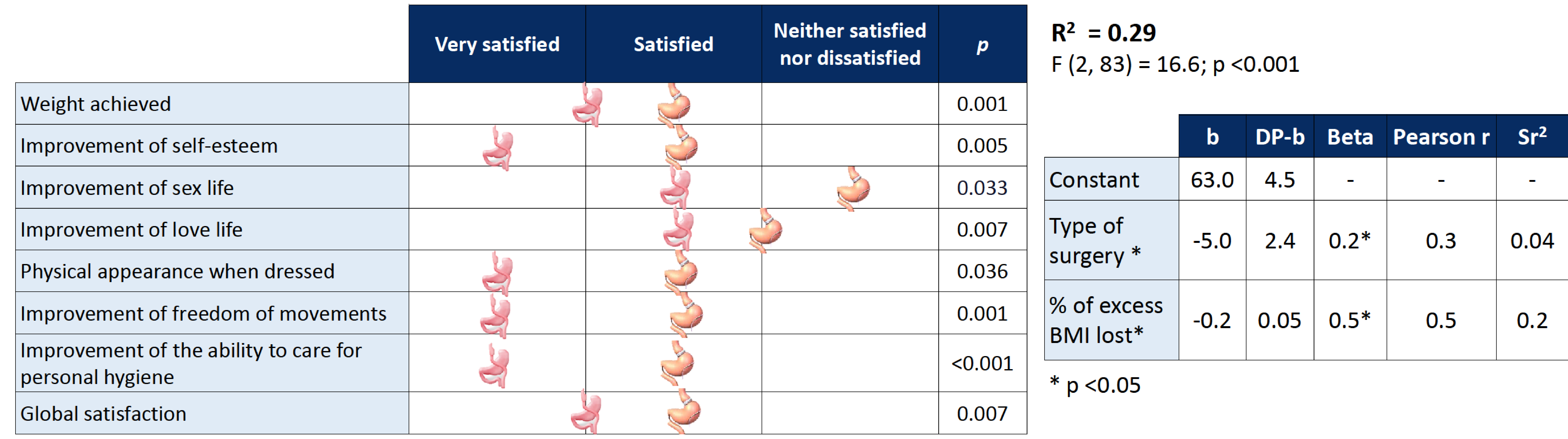

LINEAR REGRESSION ANALYSIS

$R^{2}=0.29$

b DP-b Beta Pearson $\mathbf{r} \mathrm{Sr}^{2}$

CONCLUSION

The percentage of excess BMI lost, the type of surgery and patient's age influenced post-bariatric surgery satisfaction. However, these only partially explain treatment satisfaction. Other factors, namely psychosocial, are probably also involved. 